\title{
Neglected Traumatic Atlantoaxial Rotatory Dislocation in Adult: A Case Report
}

\author{
RAGHAV SINGLA, MCH, NIVEDITHA MANJUNATH, MBBS, RAVI SHARMA, MBBS, \\ SHASHWAT MISHRA, MCH \\ Department of Neurosurgery, All India Institute of Medical Sciences, New Delhi
}

\begin{abstract}
Atlantoaxial rotatory dislocations (AARDs) are common in the pediatric population and rarely seen in adults. We describe a case of neglected AARD and subsequent management. A 25-year-old man developed a Fielding type 1 AARD following a road traffic accident. He was managed conservatively for 1.5 months before being referred to us. The patient underwent surgery 1.5 months after the accident. Closed reduction failed and C1-2 fixation with the Harms technique was performed after intraoperative reduction resulting in correction of deformity. Delay of treatment makes intraoperative reduction more difficult and increases the possibility of the chronic permanent change of neck muscles and ligaments. Hence, a high index of suspicion with a thorough clinical examination and judicious use of radiological investigations is paramount to the appropriate management of such cases.
\end{abstract}

Cervical Spine

Keywords: atlantoaxial dislocations, atlantoaxial rotatory dislocations, atlantoaxial rotatory fixation, Fielding type 1 AARD

\section{INTRODUCTION}

Atlantoaxial rotatory dislocation (AARD) is the rotational subluxation of $\mathrm{C} 1$ over $\mathrm{C} 2$. The pathoanatomy of AARD is related to the transverse alar ligament's (TAL) integrity. These dislocations occur more commonly in children and adolescents in whom there is a high degree of rotational behavior of $\mathrm{C} 1$ and $\mathrm{C} 2,{ }^{1}$ owing to weakness and malleability of periarticular soft tissue and increased mobility of the articular joints. In adults, they result from extreme rotation and distraction trauma of the cervical spine.

Atlantoaxial rotatory dislocation is defined as excessive movement and loss of facetal continuity between $\mathrm{C} 1$ and $\mathrm{C} 2$ as delineated by abnormal motion curves. ${ }^{2}$ Presentation is with neck pain and limited range of cervical spine motion with torticollis occurring towards the side of the dislocated facet joint. Radiographs with open-mouth views are often helpful in delineating the pathology. Dynamic computed tomography (CT) is the "gold standard" in the diagnosis of AARD, though patients' noncooperation due to severe pain is the limiting factor in performance of the same.

Closed reduction with traction should be instituted immediately to avoid the serious consequences of chronic AARD. Recurrent dislocation and incomplete reduction should be treated with posterior C1-2 fusion in the best achievable alignment. ${ }^{3}$ Occasionally they are seen in adults, especially when preexisting C1-2 instability is present or with high-energy trauma. ${ }^{1}$

\section{CASE REPORT}

A 25-year-old man was involved in a road traffic accident while riding a 2 -wheeler. $\mathrm{He}$ is alleged to have run into a stationary vehicle, after which his helmet fell off. He regained consciousness a few minutes later and helped his pillion rider. He was taken to the emergency department in another center and evaluated. Non-contrast CT of the head was normal. The patient could not move his head from its position, tilted to the right ("cock robin" position; Figure 1). He had clear consciousness and no motor paralysis or sensory disturbances. An MRI of the cervical spine was done at this time, showing atlantoaxial rotational subluxation with an intact TAL (Figure 2). A CT of the cervical spine was not done at this time. The patient was treated with conservative measures that included nonsteroidal anti-inflammatory drugs and cervical traction for 3 days. He was later discharged and advised bed rest and symptomatic measures. The head continued to be in a tilted position. 


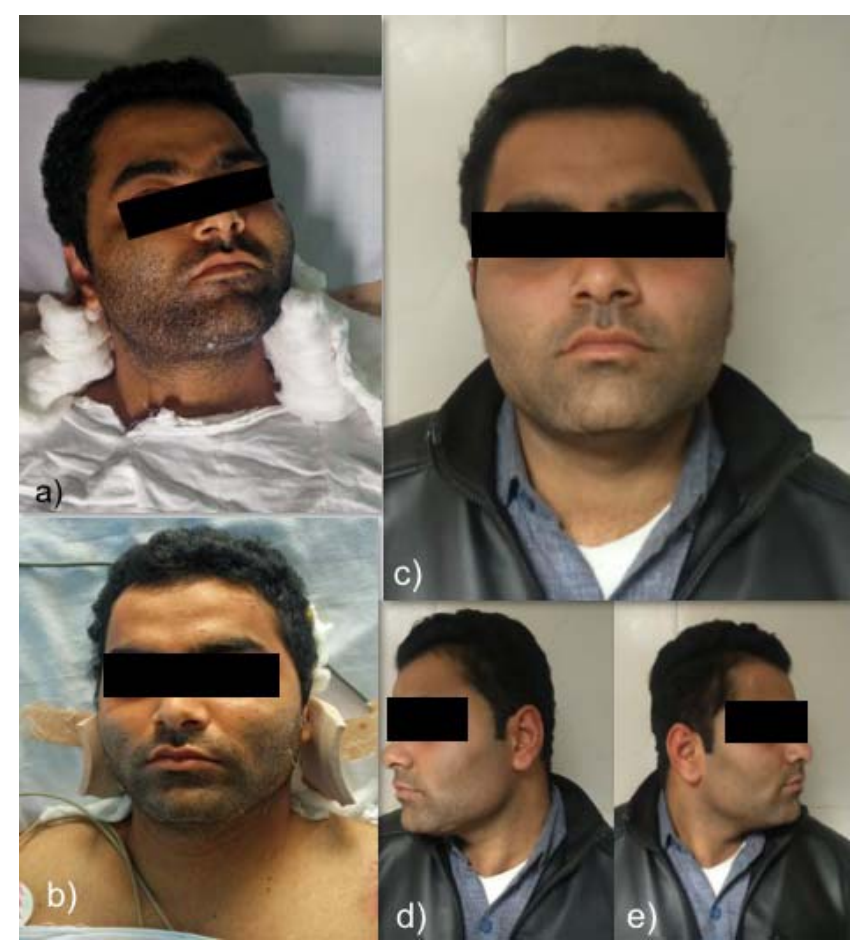

Figure 1. (a) Preoperative clinical photograph showing "cock robin" position and (b) immediately postoperative clinical photograph showing resolution of neck tilt. (c-e) Postoperative images at 2 years show no residual deformity and minimal restriction of rotation.

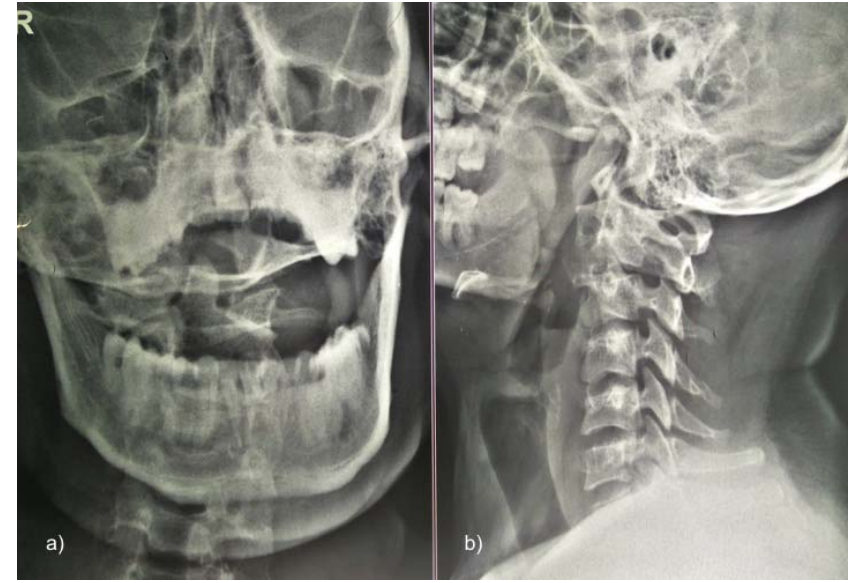

Figure 3. Preoperative x-ray: (a) Note eccentric position of the odontoid. (b) Lateral $\mathrm{x}$-ray showing rotation at $\mathrm{C} 1-2$ with elliptical appearance of the $\mathrm{C} 1 \mathrm{arch}$

The patient presented to our center after 1.5 months of having failed various treatments for the injury. At presentation, he had pain in the left $\mathrm{C} 2$ distribution and tilted cock robin position of the head but no motor deficits. An x-ray and a plain CT of the cervical spine showed the atlas rotated to the right, centering on the dens of the axis, with no increase in atlanto-dental interval (Figures 3 and 4). No developmental deformities were observed. The CT angiography showed normal course of

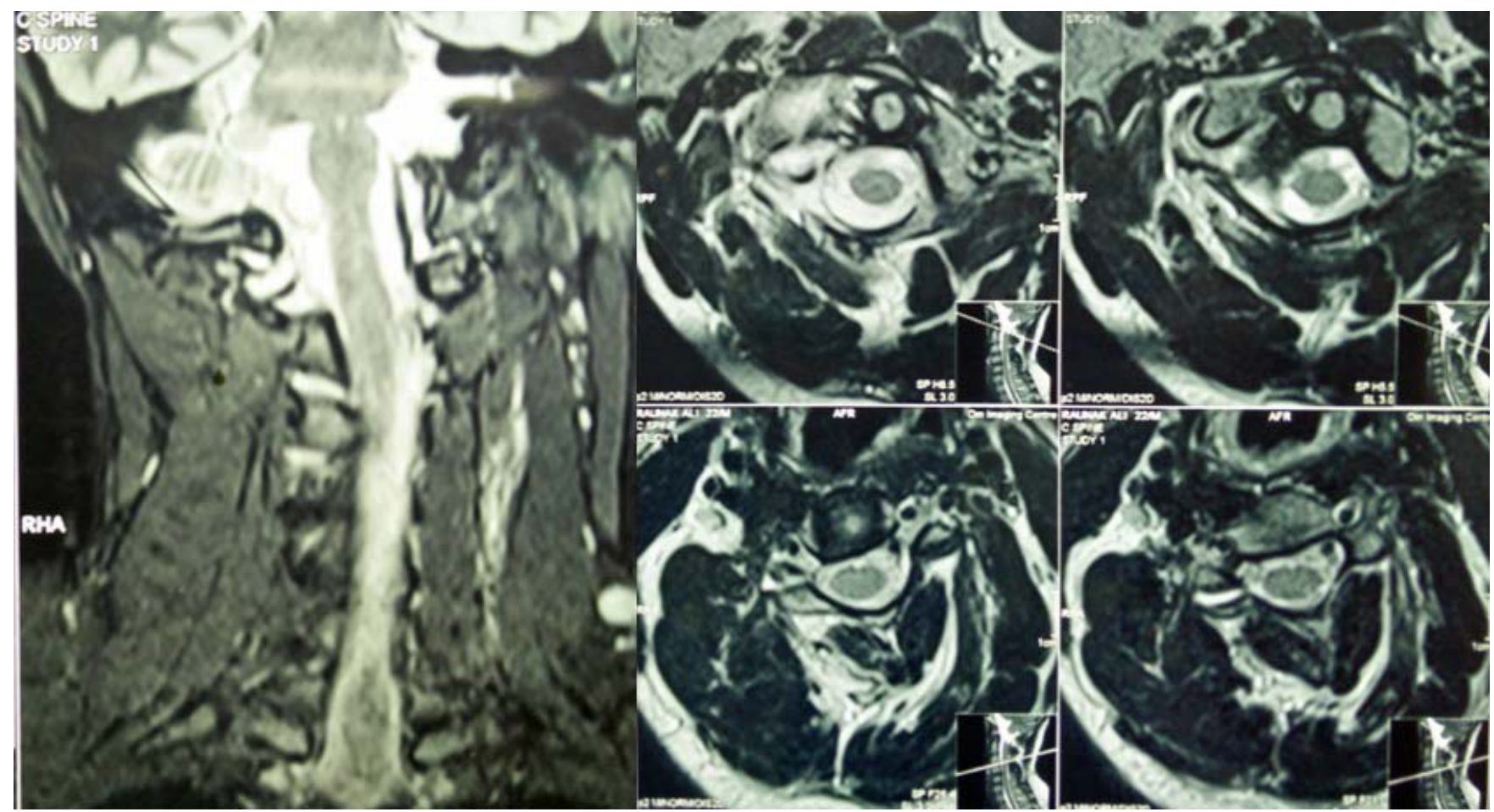

Figure 2. Preoperative MRI: (a) Coronal scans showing lateral tilt. (b) T2 weighted axial scans showed intact transverse alar ligament. 


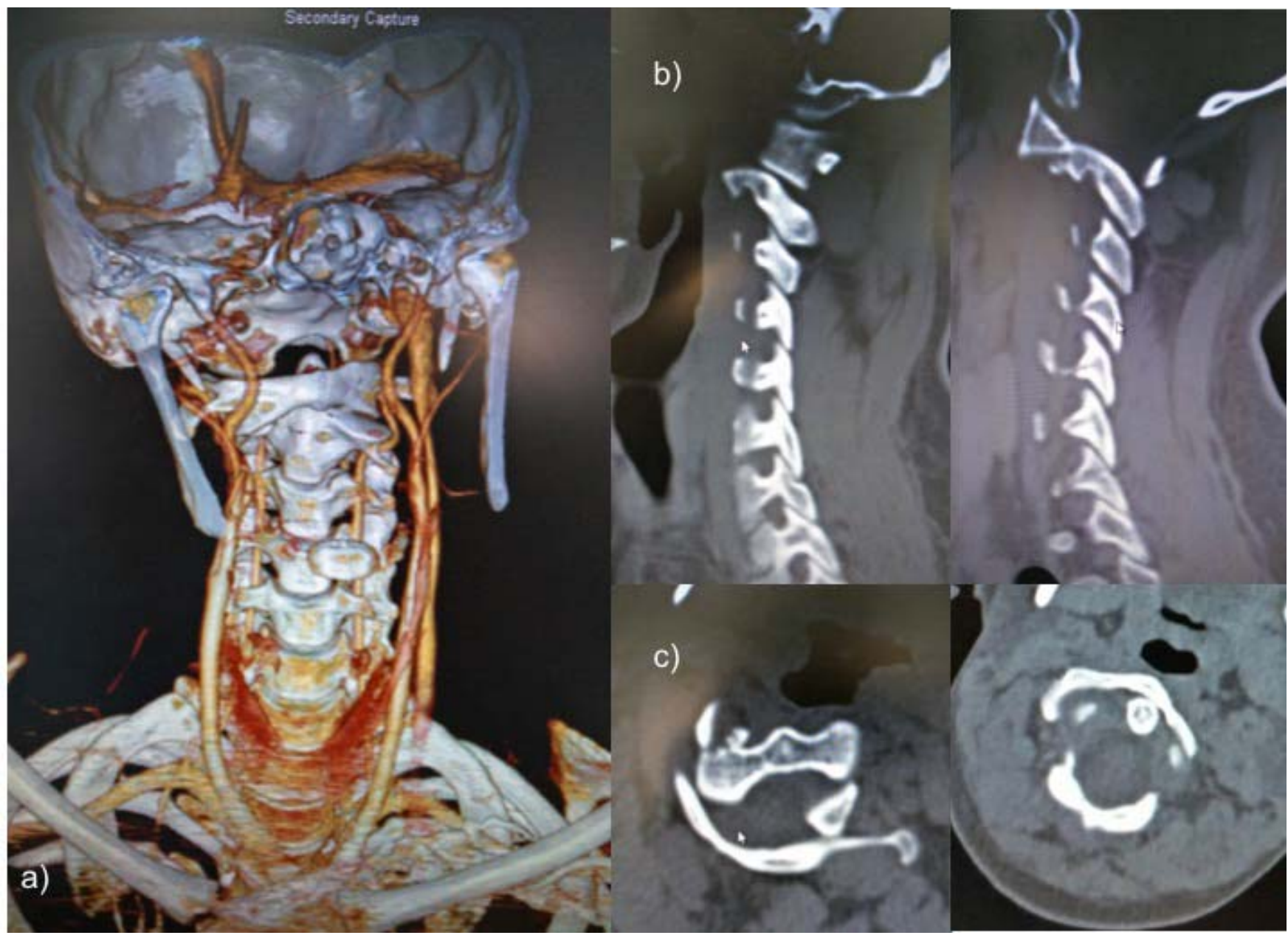

Figure 4. (a) Preoperative computed tomography angiography with 3-dimensional recon showing atlantoaxial rotatory dislocations. (b) Parasagittal view showing dislocation of facet joints. (c) Axial view showing maintained atlanto-dental interval with rotatory atlanto-axial dislocation.

vertebral arteries. This corresponded to a diagnosis of Fielding type $1 \mathrm{AARD}^{4}$ or White and Panjabi unilateral combined anterior and posterior dislocation. ${ }^{5}$ The C1-2 rotation angle was around $40^{\circ}$.

Awake manipulation and attempts at correction of the deformity failed due to neck pain and associated muscle spasm. The patient was taken for surgery, and after induction the patient's head was fixed on a Sugita 4-pin head clamp and again closed reduction was attempted under general anesthesia, but it failed. The patient was placed in a slightly reversed Trendlenberg position to allow the body weight to provide traction. Consequently, we proceeded with open reduction and fixation. After muscle dissection, the sub-axial cervical spine was seen to be rotated to the left. The C1-2 posterior atlantoaxial membrane was cut and the atlantoaxial joints were traced. The right $\mathrm{C} 1$ lateral mass was found to be perched anterior to the $\mathrm{C} 2$ pars. The rotational deformity had severely stretched the left $\mathrm{C} 2$ nerve, which was divided to expose the C1-2 interval. The $\mathrm{C} 1$ arch was found resting upon the $\mathrm{C} 2$ pars on the right side. A periosteal elevator was inserted into the space between the arch of the atlas and the $\mathrm{C} 2$ pars and rotated to achieve a distraction effect and release the perched $\mathrm{C} 1$ facet. This resulted in spontaneous derotation and correction of the deformity. The C1-2 joint spaces were then denuded of cartilage in preparation for fusion. Posterior fixation was done using the Goel-Harms C1-2 fixation technique. ${ }^{6}$ Following the surgery, the patient's neck pain subsided and the normal neck alignment was restored (Figure 5-7).

\section{DISCUSSION}

Atlantoaxial rotatory dislocations are posttraumatic pathologies resulting from rotatory trauma at C1-2 bone-ligament complexes. Physiologically, the 


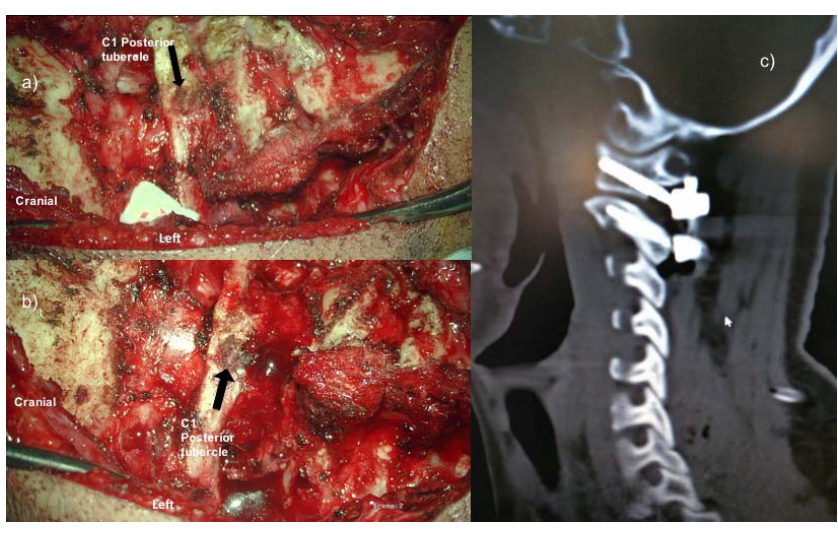

Figure 5. (a) Initial exposure depicting severe rotation of sub-axial spine in relation to $\mathrm{C} 1$. (b) Following opening of joint spaces $\mathrm{C} 1-2$ realignment noted. (c) Postoperative computed tomography scan.

C1-2 joint is responsible for as much as $60 \%$ of the total rotation of the neck, behaving as the main rotational pivot of the cervical spine. The stability of the C1-2 joint is ensured by the atlas transverse ligament having high resistance against flexion and extension, by the alar ligaments limiting lateral flexion movements, and by the joint capsules limiting rotatory movements. In the absence of an intervertebral disc between atlas and axis, any rotational stress is transmitted through the articular facets and $\mathrm{O}-\mathrm{C} 1$ joints. Excessive rotational forces may lead to capsular distraction and subsequently, AARD. In children, this condition is responsive to conservative measures and traction in view of the more elastic and slack joints ligaments and also weak periarticular soft tissue. ${ }^{7}$

AARDs are rare in adults and often the result of high-energy trauma. ${ }^{8}$ The small number of cases described in the literature may be attributable to the lethality of injuries producing traumatic AARDs. Mazzarra and Fielding ${ }^{9}$ have showed that the relative atlantoaxial rotation beyond $63^{\circ}$ results in narrowing of the spinal canal and neural injury. However, cases have been described as a result of seizure, ${ }^{10}$ Grisel syndrome, ${ }^{11}$ and cervical dystonia. ${ }^{12}$ Diagnosis of AARD is often delayed as a result since it is an uncommon occurrence and manifests as subtle findings on conventional $\mathrm{x}$ rays. $^{4,13}$ Unilateral atlantoaxial subluxations are possible with a ruptured TAL. The ligament is intact in bilateral subluxations. On a lateral view, the rotational dislocation of the atlas leads to an

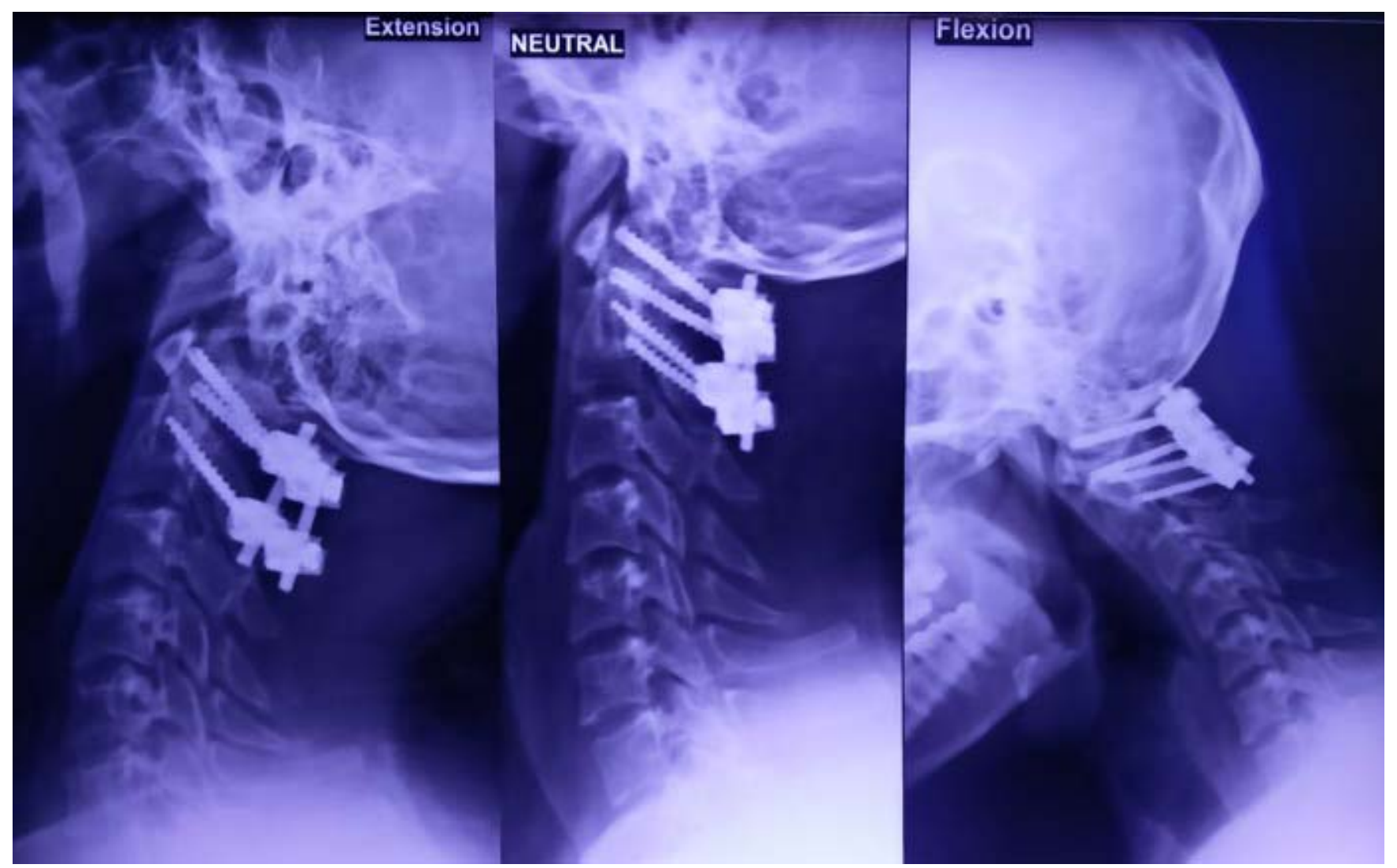

Figure 6. Postoperative $\mathrm{x}$-ray images at 2 years in extension, neutral, and flexion. 


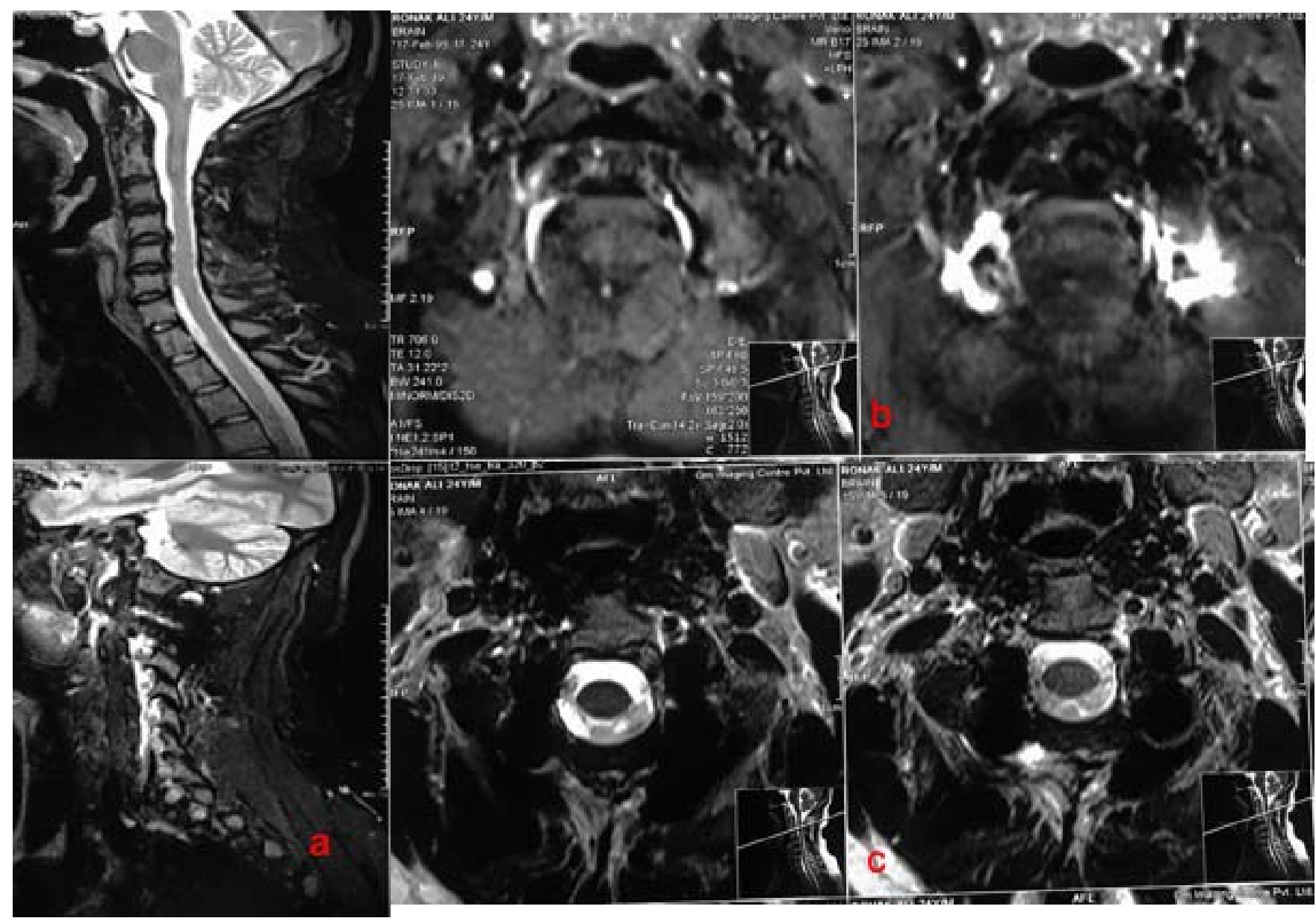

Figure 7. Postoperative MRI images at 3 years: (a) Sagittal scans of brainstem. (b) T2 weighted axial scans at foramen magnum level. (c) T2 weighted axial scans at C2 level.

elliptical appearance of the arch. Eccentric position of the odontoid process will be seen on true anterior-posterior view on plain radiographs. In a patient with persistent posttraumatic torticollis, a high index of suspicion of AARD must be maintained. A 3-dimensional CT scan must be performed to diagnose and classify the dislocation and evaluate $\mathrm{C} 0-1$ and $\mathrm{C} 1-2$ joints. ${ }^{2,14}$ An MRI scan is needed to evaluate transverse and alar ligaments, the articular facets, and periarticular edema. In addition, CT or MR angiography is needed to evaluate the exact status of vertebral arteries.

Most cases of adult posttraumatic AARD have been managed nonoperatively, ${ }^{8,15-22}$ whereas 2 cases having associated odontoid fractures ${ }^{23,24}$ and 1 having articular facet fracture ${ }^{25}$ were managed with open reduction and posterior fixation. For irreducible AARD, open reduction and fixation may become mandatory. Many surgical approaches are described for the treatment of AARDs. The posterior approach with the Harms fixation is the gold standard in fixed luxations, achieving a complete realignment and a robust stabilization. It allows intraoperative manipulation and reduction. Other authors ${ }^{26}$ have described reduction and fixation using extreme lateral approach. Weißkopf et $\mathrm{al}^{27}$ have used transoral reduction followed by temporary transoral fixation or definitive fusion in their series of pediatric and adult AARD.

Delay in reduction of more than 1 month in an adult results in a more difficult intraoperative reduction and could have clinical consequences. The delay in reduction and the cervical muscle spasm caused permanent changes that set the fixation. It would explain the failure of conservative treatment. Goel et $\mathrm{al}^{28}$ have discussed the detrimental effects of a delayed diagnosis of AARD and the success of facetal manipulation, distraction and 
realignment with fixation under surgical vision in the same. The abnormal degree of atlantoaxial rotation in our case and the failure of initial conservative approach to the same necessitated the surgical intervention.

Weißkopf et $\mathrm{al}^{27}$ showed that when fixation between $\mathrm{C} 1$ and $\mathrm{C} 2$ is demonstrated, the success rate of conservative treatment decreases in proportion to the delay in treatment. In our case too, the delay in diagnosis and treatment necessitated the need for operative intervention. Unless the CT imaging demonstrates fusion between the subluxated elements, a posterior approach for operative reduction and stabilization of the deformity is fairly simple and straightforward. The sacrifice of the stretched $\mathrm{C} 2$ root is often necessary for access to the luxated atlantoaxial joints. Possibly, the demonstration of a perched $\mathrm{C} 1$ facet may predict the failure of conservative management and attempts at closed reduction.

\section{CONCLUSION}

Atlantoaxial rotatory dislocations are rare in adults. Early diagnosis and treatment can allow closed reduction and bracing as an optimal treatment. High success rates have been reported with conservative therapy in patients with promptly diagnosed, stable, rotatory atlantoaxial dislocation not associated with transverse ligament disruption. When reduction is not possible, it is advisable to perform surgery as soon as possible to reduce the dislocation and stabilize the joint. Delay in treatment is associated with worse outcome and permanent changes in muscle and ligaments. We would like to stress the importance of evaluation of posttraumatic torticollis in adults by specialists and the need to maintain a high index of suspicion for AARD.

\section{REFERENCES}

1. Pang D, Li V. Atlantoaxial rotatory fixation: part 1biomechanics of normal rotation at the atlantoaxial joint in children. Neurosurgery. 2004;55(3):614-625, discussion 625626.

2. Pang D, Li V. Atlantoaxial rotatory fixation: part 2-new diagnostic paradigm and a new classification based on motion analysis using computed tomographic imaging. Neurosurgery. 2005;57(5):941-953, discussion 941-953.

3. Pang D, Li V. Atlantoaxial rotatory fixation. Part 3-A: prospective study of the clinical manifestation, diagnosis, management, and outcome of children with atlantoaxial rotatory fixation. Neurosurgery. 2005;57(5): 954-972, discussion 954-972.

4. Fielding JW, Hawkins RJ. Atlanto-axial rotatory fixation (Fixed rotatory subluxation of the atlanto-axial joint). $J$ Bone Joint Surg Am. 1977;59(1):37-44.

5. White AA, Panjabi M. Clinical Biomechanics of the Spine. 2nd ed. Philadelphia: LWW; 1990.

6. Harms J, Melcher RP. Posterior C1-C2 fusion with polyaxial screw and rod fixation. Spine. 2001;26(22):2467-2471.

7. Landi A, Pietrantonio A, Marotta N, Mancarella C, Delfini R. Atlantoaxial rotatory dislocation (AARD) in pediatric age: MRI study on conservative treatment with Philadelphia collar - experience of nine consecutive cases. Eur Spine J. 2012;21(suppl 1):94-99.

8. Singh VK, Singh PK, Balakrishnan SK, Leitao J. Traumatic bilateral atlantoaxial rotatory subluxation mimicking as torticollis in an adult female. J Clin Neurosci. 2009; 16(5):721-722.

9. Mazzara JT, Fielding JW. Effect of C1-C2 rotation on canal size. Clin Orthop Relat Res. 1988;237:115-119.

10. Tarantino R, Donnarumma P, Marotta N, et al. Atlanto axial rotatory dislocation in adults: a rare complication of an epileptic seizure - case report. Neurol Med Chir (Tokyo) 2014;54(5):413-416.

11. Shunmugam M, Poonnoose S. Spontaneous atlantoaxial subluxation associated with tonsillitis. Asian $J$ Neurosurg. 2015;10(2):139-141.

12. Tonomura Y, Kataoka H, Sugie K, Hirabayashi H, Nakase H, Ueno S. Atlantoaxial rotatory subluxation associated with cervical dystonia. Spine. 2007;32(19):E561-E564.

13. Engelhardt P, Fröhlich D, Magerl F. Atlanto-axial rotational subluxation in children: therapy in delayed diagnosis [in German]. Z Fur Orthop Ihre Grenzgeb. 1995;133(3):196201.

14. Radcliff K, Kepler C, Reitman C, Harrop J, Vaccaro A. CT and MRI-based diagnosis of craniocervical dislocations: the role of the occipitoatlantal ligament. Clin Orthop Relat Res. 2012;470(3):1602-1613.

15. Castel E, Benazet JP, Samaha C, Charlot N, Morin O, Saillant G. Delayed closed reduction of rotatory atlantoaxial dislocation in an adult. Eur Spine J. 2001;10(5):449-453.

16. Jeon SW, Jeong JH, Moon SM, Choi SK. Atlantoaxial rotatory fixation in adult patients. J Korean Neurosurg Soc. 2009;45(4):246-248.

17. Marti JJ, Zalacain JF, Houry DE, Isakov AP. A 24-yearold woman with neck pain. Am J Emerg Med. 2001;29(4):473. e1-2.

18. Sinigaglia R, Bundy A, Monterumici DAF. Traumatic atlantoaxial rotatory dislocation in adults. Chir Narzadow Ruchu Ortop Pol. 2008;73(2):149-154.

19. Venkatesan M, Bhatt R, Newey ML. Traumatic atlantoaxial rotatory subluxation (TAARS) in adults: a report of two cases and literature review. Injury. 2012;43(7):1212-1215.

20. Bellil M, Hadhri K, Sridi M, Kooli M. Traumatic atlantoaxial rotatory fixation associated with $\mathrm{C} 2$ articular facet fracture in adult patient: case report. J Craniovertebr Junction Spine. 2014;5(4):163-166.

21. Lefebvre Y, Babin SR, Clavert $P$, et al. Traumatic bilateral rotatory $\mathrm{C} 1-\mathrm{C} 2$ dislocation in an adult: case report and review of the literature [in French]. Rev Chir Orthop Reparatrice Appar Mot. 2002;88(6):613-619. 
22. Wise JJ, Cheney R, Fischgrund J. Traumatic bilateral rotatory dislocation of the atlanto-axial joints: a case report and review of the literature. J Spinal Disord. 1997;10(5):451-453.

23. Goel A, Figueiredo A, Maheshwari S, Shah A. Atlantoaxial manual realignment in a patient with traumatic atlantoaxial joint disruption. J Clin Neurosci. 2010;17(5):672673.

24. Fuentes S, Bouillot P, Palombi O, Ducolombier A, Desgeorges M. Traumatic atlantoaxial rotatory dislocation with odontoid fracture: case report and review. Spine. 2001;26(7):830-834.

25. Kim Y-S, Lee J-K, Moon S-J, Kim S-H. Post-traumatic atlantoaxial rotatory fixation in an adult: a case report. Spine. 2007;32(23):E682-E687.

26. Crockard HA, Rogers MA. Open reduction of traumatic atlanto-axial rotatory dislocation with use of the extreme lateral approach. A report of two cases. J Bone Joint Surg Am. 1996;78(3):431-436.

27. Weißkopf M, Naeve D, Ruf M, Harms J, Jeszenszky D. Therapeutic options and results following fixed atlantoaxial rotatory dislocations. Eur Spine J. 2005;14(1):61-68.

28. Goel A, Jain S, Shah A. Management of a case of neglected atlantoaxial rotatory dislocation. Neurol India. 2017;65(5):1170-1173.

Disclosures and COI: The authors received no funding for this study and report no conflicts of interest.

Corresponding Author: Dr Shashwat Mishra, Room No. 720, CN Centre, Department of Neurosurgery, All India Institute of Medical Sciences, New Delhi, India. Phone: +91 (986) 839-8590; Fax: 01126593291; Email: gyrusrectus@gmail.com.

Published 29 February 2020

This manuscript is generously published free of charge by ISASS, the International Society for the Advancement of Spine Surgery. Copyright (C) 2020 ISASS. To see more or order reprints or permissions, see http://ijssurgery.com. 